\title{
A Memorial to A. H. Black
}

O'Keefe and Nadel's cognitive map theory of the hippocampus might not have achieved its current status without the careful contributions of Abe Black. His name appeared on two theoretical review articles that helped bring the cognitive map theory to the fore (Black, Nadel, \& O'Keefe, 1977; Nadel, O'Keefe, $\&$ Black, 1975). These articles grew out of a collaborative relationship between Abe and O'Keefe and Nadel's group at University College London (UCL).

Articles relevant to experimental tests of the theory emerged from his laboratory at McMaster University up to the time of his death in the summer of 1978 . In fact, Paul Solomon and I originally wrote to Abe that spring to find out whether he would sponsor the workshop ultimately held in Williamstown. Lynn Nadel answered our letter, indicating that Abe supported the idea but would not be able to participate. The list of participants and other arrangements grew from correspondences among Solomon, Nadel, and myself.

I recall the last time I spoke with Abe. It was at a meeting of the Eastern Psychological Association in
1976, and I sought his advice about whether I should spend my upcoming sabbatical leave at UCL or whether I should choose from a couple of other options. Abe's enthusiasm for UCL carried the day. I went to UCL, although not to O'Keefe's laboratory. There I met O'Keefe, and the personal connection between the cognitive-map theorists and the classical conditioning group concerned with the hippocampal function helped to foster the amicable and helping atmosphere that prevailed during the workshop.

John W. Moore

\section{REFERENCES}

Black, A. H., NAdel, L., \& O'Keefe, J. Hippocampal function in avoidance learning and punishment. Psychological Bulletin, 1977, 84, 1107-1129.

Nadel, L., O'Keefe, J., \& Black, A. Slam on the brakes: A critique of Altman, Brunner and Bayer's response inhibition model of hippocampal function. Behavioral Biology, 1975, 14, 151-162. 